\title{
Obituary
}

\section{Dra. Elsa Beatriz Abuin Saccomano}

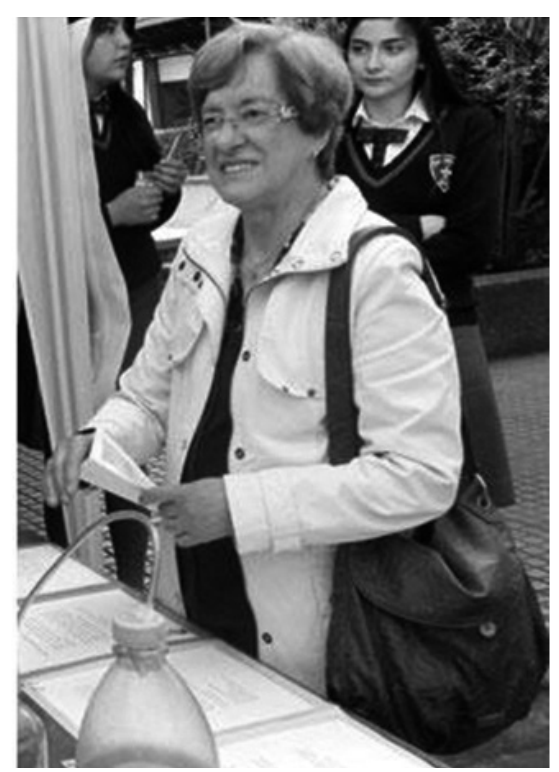

Elsa Abuin Saccomano studied at the University of Buenos Aires, Argentina and obtained her BSc in Chemistry in 1966. As an excellent student with great talent for chemistry, she decided to pursue a doctorate by choosing the Kinetics and Photochemistry Group led by Drs. Grateworld and Lissi. From that until her illness, two themes to which she devoted much of her life.

Political issues in Argentina to which University was particular sensitive, made the research group move to Chile, rigth after the tragic night of the long sticks, on July 29th (the night when the military broke into the College of Sciences at the University of Buenos Aires). The whole group came to the then Universidad Técnica del Estado (UTE), Elsa despite of her youth and being new in the group did not hesitate and moved along with them to Chile as well.

On June 1st of 1968, Dr. Abuin was hired as a professor in the Department of Engineering of the then UTE. From that day, quickly Professor Abuin began to carve out a successful career as academic and scientific: she was one of the first students on obtaining a $\mathrm{PhD}$ in Chemistry at the University of Chile with the dissertation entitled "Fotoquimica de cetonas alifaticas en fase gaseosa" (Gas-phase photochemistry of aliphatic ketones) under Eduardo Lissi's supervision and defended in 1974. Thus, in few years the student became graduate professor at the UTE. In this University she developed a successful scientific career supervising and mentoring numerous undergraduate and graduate students, clearly she was one of the vital members of the research group that up to now maintains the historic name of "Kinetics and Photochemistry" located in the current Faculty of Chemistry and Biology of the University of Santiago of Chile.

In the early ' 90 s Elsa Abuin was the first woman in Chile being awarded with a Guggenheim Fellowship to conduct scientific work abroad, working as an Associate Researcher at the University of Rochester, USA and at the University of Ottawa, Canada. She was also visiting professor at the National University of Rio Cuarto, Argentina and University of Sao Paulo, Brazil. Her 46 years of career and devoted scientific work is summarized in more than 150 publications in international journals as well as monographs, reviews, conferences participation and seminars. During her career and since the gubernamental financial program for founding research in Chile in 1982 stars, she was Principal Researcher and co-investigator of several FONDECYT projects, she led many others projects financed by the University, the Andes Foundation, and international agencies such as the
CONICET and CNPQ among others. She was a conspicuous International conferences organizer being one of the co-founders of the Encuentros Latinoamericanos de Fotoquimica, the last one carefully organized by her in 2010, held in La Serena.

Elsa also was renowned for her outstanding teaching skills, she was always able to explain abstract and complex concepts on physical organic chemistry clear and nicely, these qualites were printed in some of the writter chapters by her in the series of books on Physical Chemistry edited by Dr. Eduardo Lissi, the last one recently released on June 27, 2013 finds her as editor, in words of Eduardo Lissi in his tribute "the serie of these 4 volumes would have been impossible to be achieved without having her as main contributor". The serie published by the Universidad de Santiago de Chile since 2003 is enormuosly valued by undergraduate students, she had such a vocation for teaching that earned her awards granted by the Vicerectoría Académica and constant recognition of her students.

She was also Director of the Graduate Program of the Faculty of Chemistry and Biology having the acknowledgement and respect of the whole scientific community, Elsa remains active until two weeks before her death. Thus, there are publications of this year and two or three manuscripts were being reviewed at this time, and the research plan was beginning to draw for the proposal to be presented to the FONDECYT 2012 convocatory.

These lines dedicated to Professor Elsa Abuin, the academic, Professor Titular, the leading researcher, authorized word on physical-chemistry matter, photochemistry, colloidal systems, would provide an incomplete and biased view of Elsa if were not mentioned some and her many others qualities: Elsa daily, vital member of the Laboratory of Kinetics and Photochemical, academic and women of great strength, courage specially during the dark period of our country by protecting students exposed to arbitrariness. Elsa concerned of the most incredible and welfare of her students. Elsa of great patience and very little patience, Elsa argumentative showing her large capacity to defend their thoughts, Elsa serious and cheerful, kind, gentle, warm personality. Elsa able to explain complicated things in simple words, even adding a touch of beauty product of her great mental clarity. Students, colleagues and staff of the Faculty of Chemistry and Biology, and chemist community have lost a prominent academic and especially a noble human being. 